\title{
Avaliação da Feira de Ciências de Roraima enquanto espaço de Divulgação Científica
}

\author{
Evaluation of the Roraima Science Fair as a Space for Scientific \\ Dissemination
}

\author{
Aluizio Andrade de Castro Junior (aluiziojunior1991@gmail.com) \\ Universidade Estadual de Roraima (UERR) \\ Monica Feitosa da Costa Sousa (monikkafeitosa01 @ gmail.com) \\ Universidade Estadual de Roraima (UERR) \\ Bianca Maíra de Paiva Ottoni Boldrini (biaboldrini.2@gmail.com) \\ Colégio de Aplicação/CEDUC - Universidade Federal de Roraima (UFRR) \\ Ivanise Maria Rizzatti (niserizzati@gmail.com) \\ Universidade Estadual de Roraima (UERR)
}

\begin{abstract}
Resumo:
O objetivo desta pesquisa, foi avaliar como os projetos foram elaborados para a Feira de Ciências Estadual de Roraima (FECIRR) enquanto espaço de divulgação científica. Esta pesquisa foi desenvolvida no Park Anauá, que se localiza no município de Boa Vista - Roraima, no mês de novembro de 2018. Para a realização deste trabalho, abordou-se a pesquisa de cunho qualitativo, quantitativo descritivo, já em relação aos procedimentos técnicos, utilizamos o estudo de campo. Este trabalho, envolveu a participação de oito (8) professores de oito (8) escolas privadas da capital que participaram da FECIRR. Constata-se que os professores apresentam concepções diferentes sobre Feira de Ciências, mas por terem pontos de vista heterogêneos a maioria já tem uma certa experiência como planejar, desenvolver e executar os projetos a serem apresentados. Na realização dos projetos os alunos são responsáveis pela escolha do tema a ser trabalhado na pesquisa e durante esse processo o professor fica responsável pelas orientações. Os alunos participam de forma plena no desenvolvimento do projeto e são bastante motivados e criativos, o tempo de realização dos projetos varia de dois a mais de quatro 4 meses de estudo e pesquisa o que vem a contribuir para uma aprendizagem científica e tecnológica dos alunos.
\end{abstract}

Palavras-chave: Investigação Científica; Projeto; Ciências.

\section{Abstract:}

The objective of this research was to evaluate how the projects were prepared for the State Science Fair of Roraima (FECIRR) as a space for scientific dissemination. This research was developed in Park Anauá, located in the municipality of Boa Vista - Roraima, in the month of November 2018. For the accomplishment of this work, we approached the qualitative, descriptive quantitative research, already in relation to the technical procedures, we used the field study. This work involved the participation of eight (8) teachers from eight (8) private schools in the capital that participated in the FECIRR. It is observed that teachers present different conceptions about Science Fair, but because they have heterogeneous points of view the majority already has a certain experience how to plan, to develop and to execute the projects to be presented. In carrying out the projects the students are responsible for choosing the topic 
to be worked on in the research and during this process the teacher is responsible for the guidelines. The students participate fully in the development of the project and are highly motivated and creative, the time of the projects varies from two to more than four months of study and research, which contributes to the students' scientific and technological learning.

Key words: Scientific Research; Project; Sciences.

\section{INTRODUÇÃ̃}

O termo Feira é aplicado geralmente para indicar locais onde se expõem e se vendem mercadorias. As Feiras de Ciências ocorrem em locais públicos onde os alunos, após uma atividade de investigação científica, expõem e discutem suas descobertas e resultados, podendo também colocá-lo a disposição da comunidade. Isso possibilita aos alunos expositores oportunidades de crescimento científico, cultural e social. Atualmente, essas exposições têm-se tornado cada vez mais frequentes nas escolas, sejam estas públicas ou particulares, de ensino fundamental ou médio. A realização de Feiras de Ciências é perfeitamente justificada ao considerar-se: os objetivos de Ensino de Ciências: desenvolvimento do pensamento lógico; vivência do método científico; universalidade das leis científicas; conhecimento do ambiente e a sondagem de aptidões; a preparação para o trabalho e a integração do indivíduo na sociedade (PEREIRA et al. 2000).

Acrescenta-se a este entendimento a perspectiva de Maria Julieta Ormastroni, que é vista como uma entre as maiores referências relacionadas a Educação Científica. Para Ormastroni (1990 p.17) a Feira de Ciências:

\footnotetext{
"É uma exposição pública de trabalhos científicos e culturais realizados por alunos. Estes efetuam demonstrações, oferecem explicações orais, contestam perguntas sobre os métodos utilizados e suas condições. Há troca de conhecimentos e informações entre alunos e o público visitante." (ORMASTRONI, 1990, p. 7).
}

Para Sousa (2015, p. 17) as Feiras de Ciências são consideradas "um instrumento de grande relevância para o processo de ensino aprendizagem de Ciências quando realizadas nos espaços não-formais e como atividade extraclasse".

As Feiras de Ciências surgiram no Brasil na década de 60. As primeiras Feiras caracterizavam-se por apresentarem trabalhos resultantes de experiências feitas em aula 
ou montagem de aparelhos utilizados com fins demonstrativos (MANCUSO,1995). Dessa forma as Feiras de Ciências passam ser chamadas também de mostras de trabalhos escolares. De acordo com Wanderley (2001),

\footnotetext{
"A primeira tendência verificada na maioria das Feiras de Ciências brasileiras ...refere-se à manutenção do tradicional modelo das Feiras, com ênfase na formação do pequeno cientista." (WANDERLEY, 2001, p. 172).
}

Pereira et al. (2000) entendem que os objetivos da realização de Feiras de Ciências ou mostras de trabalhos escolares vão além da criticada ênfase na "formação de pequenos cientistas":

\begin{abstract}
"Como estratégia de ensino, as Feiras de Ciências são capazes de fazer com que o aluno, por meio de trabalhos próprios, envolva-se em uma investigação científica, propiciando um conjunto de experiências interdisciplinares, complementando o ensino-formal. Como empreendimento social-científico, as Feiras de Ciências podem proporciona que os alunos exponham trabalhos por eles realizados à comunidade, possibilitando um intercâmbio de informações" (PEREIRA et al. 2000, p. 38).
\end{abstract}

Nesse sentido, basicamente, as Feiras de Ciências tem como objetivo (Programa Nacional de Apoio às Feiras de Ciências da Educação Básica - FENACEB, 2006): a) estimular estudantes nas atividades de iniciação científica e tecnológica desenvolvidos na região; b) possibilitar a integração entre profissionais e estudantes da região de modo a ampliar suas relações; c) conduzir e estimular, de forma sistemática, a institucionalização do desenvolvimento científico e tecnológico dos professores e estudantes do ensino médio e profissional de nível técnico da região; d) promover a integração entre as instituições de ensino da região, bem como o meio industrial e empresarial.

Em Roraima, a primeira Feira de Ciências Estadual de Roraima (FECIRR) aconteceu em 1986 e foi organizada pelo Centro de Ciências de Roraima (CECI-RR). Participaram da exposição 17 escolas de primeiro e segundo graus, bem como, outras instituições. Como resultado percebeu-se a "necessidade de cursos de Iniciação à Educação Científica e cursos Preparatórios para a realização de Feiras de Ciências de produção científica" (SOUSA, 2015, p. 79).

Segundo Sousa (2015), o CECI-RR organizou e realizou no total 14 edições da FECIRR, nos anos de 1986 à 1998 e em 2001. Em 1997 o estado de Roraima sediou 
pela primeira vez na região norte a Feira Nacional de Ciências do Brasil (IX FENACI), e contou com a participação de 15 estados, 2402 estudantes e 531 professores. Denotando a importância do estado de Roraima no cenário brasileiro em relação às Feiras de Ciências e Divulgação Científica.

Para Albagli (1996) a Divulgação Científica tem como objetivo garantir o acesso da população aos conhecimentos da Ciência e da Tecnologia, percebendo seus impactos na sociedade e no ambiente. Já Bueno (2010, p. 5) destaca que a função da Divulgação Científica, é a de "democratizar o acesso ao conhecimento científico e estabelecer as condições necessárias para a chamada Alfabetização Científica". Considera ainda que a divulgação é um "estágio inicial para chegar à Cultura científica de maneira satisfatória".

Partindo dessa contextualização sobre as Feiras de Ciências, o objetivo desta pesquisa, foi de investigar como os projetos selecionados para a Feira Estadual de Ciências de Roraima (FECIRR) - 2018 foram elaborados, considerando a feira enquanto espaço de Divulgação Científica. Para tanto, fez-se necessário durante esse processo analisar a concepção pedagógica dos professores sobre os projetos desenvolvidos na feira, sendo imprescindível também, verificar se as feiras de Ciências contribuem para a Divulgação Científica.

\section{OS CAMINHOS DA PESQUISA}

Esta pesquisa foi desenvolvido no Park Anauá, Boa Vista - Roraima ${ }^{1}$, no mês de novembro de 2018 (Figura 1). Para a realização deste trabalho, aborda-se a pesquisa de cunho qualitativo, quantitativo e descritivo. Segundo Gil (2008) menciona que umas das peculiaridades da pesquisa descrita está na utilização de técnicas padronizadas de coleta de dados, tais como o questionário e a observação sistemática. Já em relação aos procedimentos técnicos, utiliza-se do estudo de campo que procura o aprofundamento de uma realidade especifica. É realizado por meio da observação direta das atividades do grupo estudado e de entrevistas com informantes para captar as explicações e interpretação do que ocorrem naquela realidade.

\footnotetext{
${ }^{1}$ Fonte: http://ufrr.br/mepa/index.php?option=com_content $\&$ view=article $\&$ id=63\&catid=2
} 


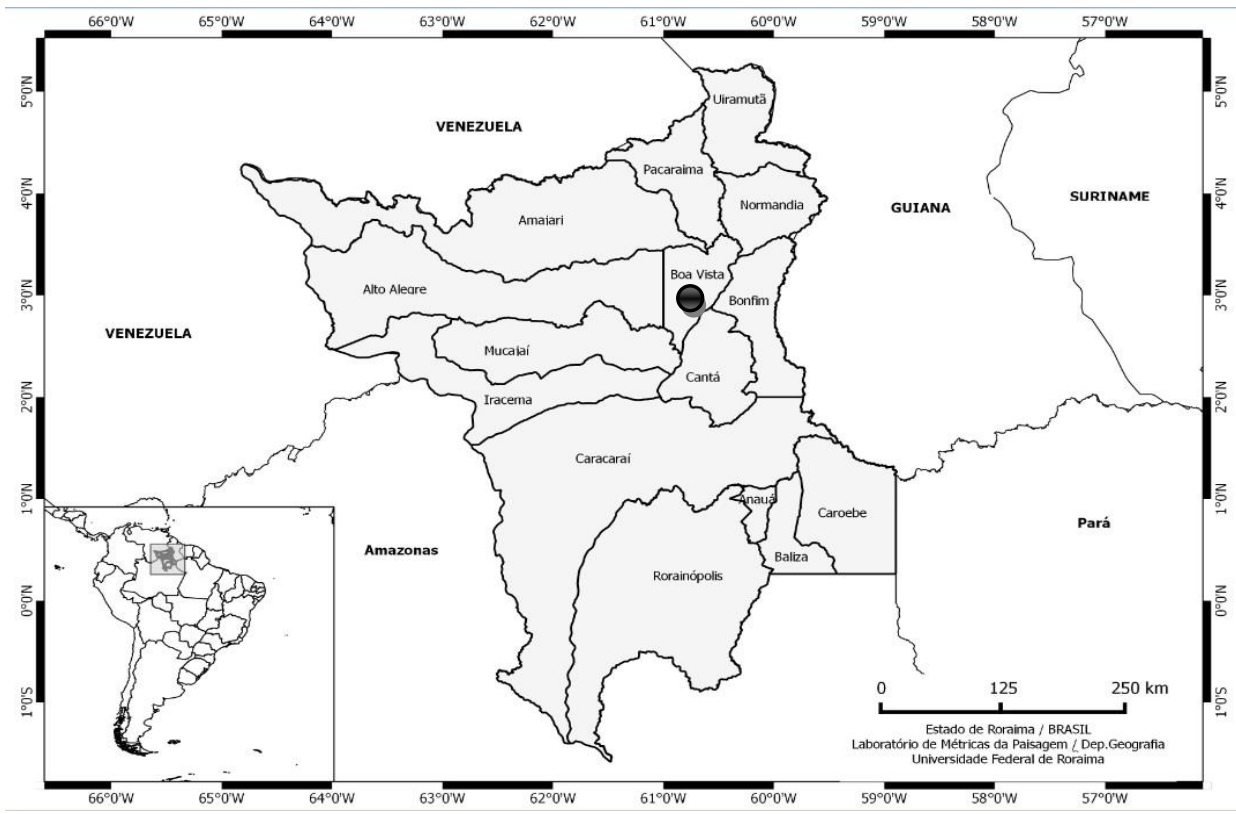

Figura 1 - Mapa do Brasil destacando o Estado de Roraima municípios de Boa Vista.

Este trabalho, envolveu a participação de oito professores de escolas privadas da capital que participaram da Feira de Ciências de Roraima enquanto espaço de Divulgação Científica no Parque Anauá. Para pesquisa com os professores, utilizamos o questionário, sendo este composto de questões cinco perguntas de múltipla escolha e seis perguntas discursiva, perfazendo-se um total de 11 perguntas (Apêndice 1). A identidade dos professores pesquisados submetidos dessa pesquisa, foi preservado por questões éticas. As análises dos dados produzidos, foram analisados com base nos objetivos deste trabalho.

\section{DIFERENTES ORGANIZAÇÕES E CONCEPÇÕES DOS PROFESSORES SOBRE FEIRA DE CIÊNCIAS}

Ao todo foram entrevistados oito professores que trabalham em escolas da rede privada da capital, e que atuam nas modalidades finais do ensino fundamental II ( $6^{\circ}$ ao $9^{\circ}$ ano) e ensino médio. Os docentes pesquisados nesta pesquisa apresentam formação em Ciências, Biologia, Português, História e Química, com atuação na educação básica a 12 anos. A primeira questão buscou saber qual o entendimento dos professores sobre as Feiras de Ciências ou mostras de trabalhos escolares? (Figura 2). 


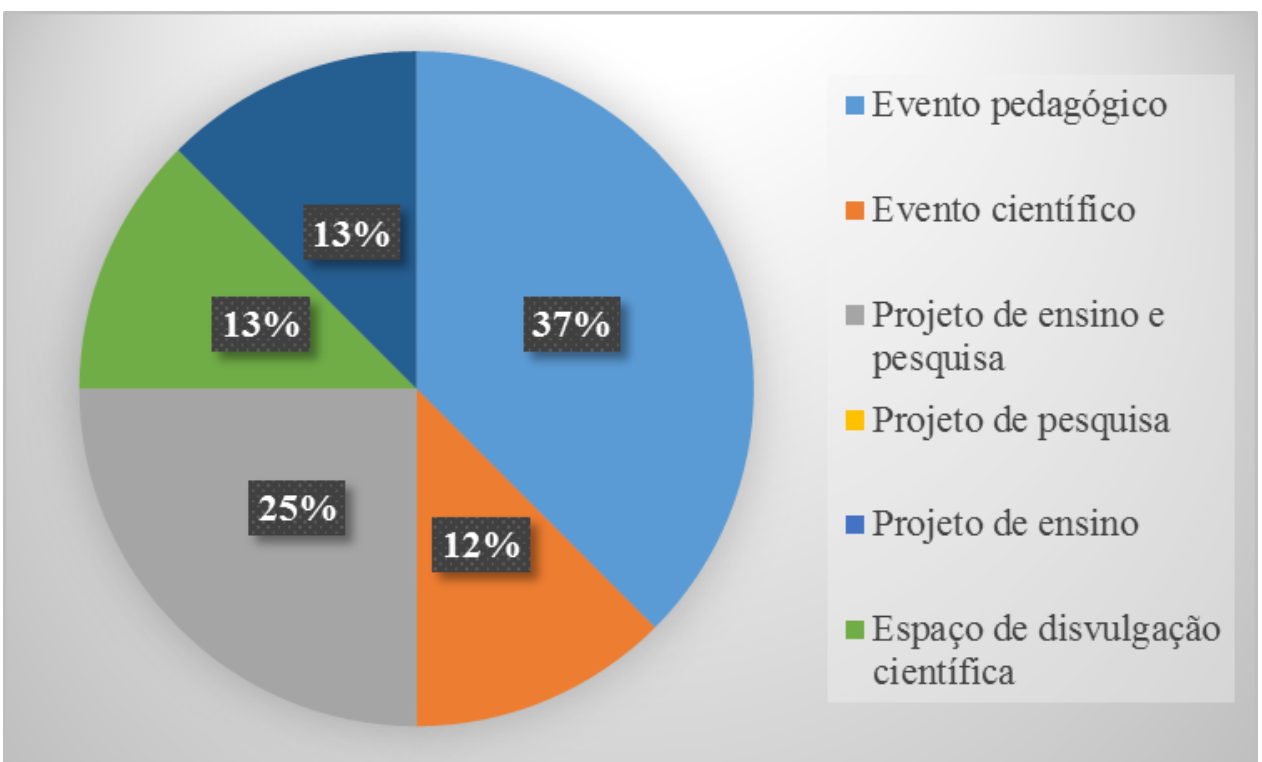

Figura 2 - Respostas dos professores de escolas privadas de Boa Vista, Roraima, sobre o que entendem por Feiras de Ciências.

Percebe-se que os professores apresentam concepções diferentes sobre Feira de Ciências, um percentual de $37 \%$ responderam que está relacionado a evento pedagógico. Portanto, a Feira de Ciências abarca todas as atividades pedagógicas mencionadas pelos professores, desde um simples evento pedagógico até um espaço de Divulgação Científica, pois todas as atividades mencionadas pelos professores tem a intensão de divulgar os trabalhos científicos e tecnológicos produzidos pelos estudantes. Neste sentido, segundo Fenaceb (2006):

As Feiras de Ciências são conhecidas hoje como atividade pedagógica e cultural com elevado potencial motivador de ensino e da prática científica no ambiente escolar. Tanto para alunos e professores, quanto para a comunidade em geral, as feiras vêm constituindo uma oportunidade de aprendizagem e de entendimento sobre as etapas da construção do conhecimento cientifico (p. 07).

Dando continuidade, buscou-se saber se os professores já participaram de Feiras de Ciências como estudante? 75\% disseram que já participaram como estudante, enquanto que $25 \%$ responderam que não. Nota-se que a maioria dos professores pesquisados, já tem uma certa experiência ou relação sobre o que é Feira de Ciências, pois já tiveram a oportunidade de vivenciar esta experiência nas escolas. As Feiras de Ciências nas escolas tem se tornado um instrumento muito significativo, é a partir dela que muitos alunos começam a ter interesse em estudar Ciências. 
Nesse contexto Rosa (1995) ressalta que as Feiras de Ciências nas escolas tem sido um importante espaço pedagógico para se desenvolver o gosto pela Ciência, principalmente nas séries iniciais, pois incentivam o desenvolvimento do saber e do interesse cientifico, que deve ser iniciado pelos professores, como um importante instrumento na construção do próprio conhecimento do aluno.

A terceira questão foi relacionada a escolha do para desenvolver o projeto de pesquisa? $62 \%$ dos professores responderam que o tema do projeto é escolhido pelos alunos. Já os demais mencionaram que o tema é escolhido de acordo com o que está sendo sugerido pela Semana Nacional de Ciências e Tecnologia (SNCT) Figura 3.

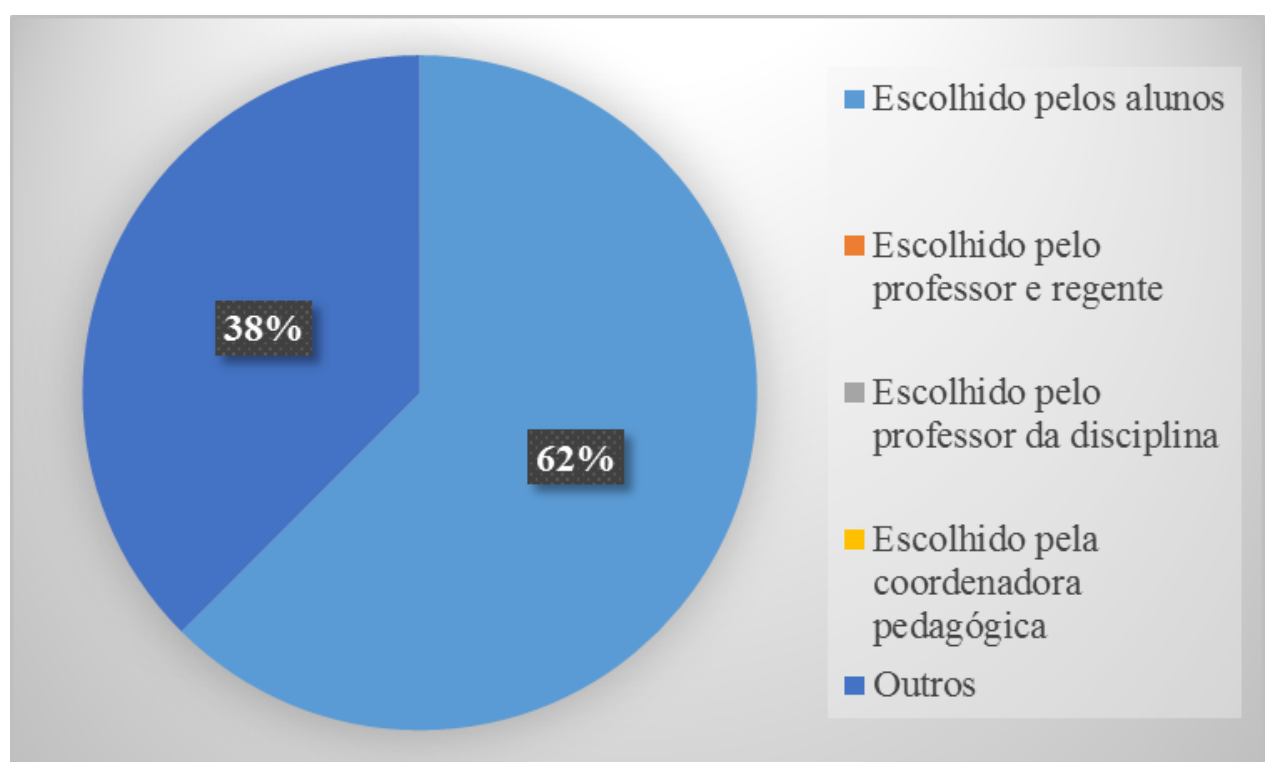

Figura 3 - Resposta dos professores de como é escolhido o tema para desenvolver o projeto de pesquisa com os estudantes

Observa-se, nas respostas pergunta desta pergunta que os alunos são responsáveis pela escolha do tema a ser desenvolvido durante a feira. Isso pode ser muito significativo, pois, os alunos irão trabalhar com os conteúdos que eles mais se identificam, isso pode potencializa uma alfabetização científica e tecnológica. Alfabetizar cientificamente, os alunos em Ciências e Tecnologia é hoje uma necessidade do mundo contemporâneo (SANTOS \& SCHINETZLER, 1997). Não se trata de mostrar as maravilhas da Ciências, mas de disponibilizar as representações que permitem aos alunos agir e tomar decisões frente as questões Científicas e Tecnológicas (FOUREZ, 1995). 
$\mathrm{Na}$ quarta pergunta, buscou-se saber como ocorre o envolvimento dos estudantes durante a realização do projeto? E de acordo com as respostas dos professores:

Professor 1 - Os alunos pesquisam muito;

Professor 2 - O tema é esclarecido, depois buscamos envolver o aluno com a pesquisa e depois vamos a prática, fazemos a coleta de dados e a confecção de materiais;

Professores 3 - Os alunos são estimulados pelos professores e participam de forma plena;

Professor 4 - ficam motivados e bastante envolvidos (professores). Etc...

Neste sentido, Rosa (1995) destaca que as escolas deveriam usar as Feiras de Ciências para desenvolver nos alunos a curiosidade, a investigação para fazer Ciências. No entanto, as Feiras de Ciências, de um modo geral são feitas por meio de projetos, desvinculadas dos conteúdos desenvolvidos em sala de aula. Estruturalmente são realizadas em forma de maquetes, exposições e reprodução de atividades experimentais, com a presença de pessoas da comunidade. De uma forma extremamente estética diminuindo assim a capacidade da escola de ser considerada como o espaço ideal para a Divulgação Científica, mas para a formação crítica e exercício da cidadania ao proporcionar a discussão e reflexão de problemas sociais.

Logo em seguida, buscou-se saber como ocorre o processo de orientação durante a realização do projeto?

Professor 1 - Em 15 em 15 dias ocorre um encontro para orientação;

Professor 2 - Durante as aulas, sempre 15 minutos antes para falar do projeto;

Professor 3 - São orientados durante as aulas e em horário oposto;

Professor 4 - Auxilio no começo do projeto e controlo o planejamento;

Professor 5 - (1 uma) vez por semana" (professores). Etc...

Diante das resposta dos professores, percebe-se que os alunos são orientados durante o desenvolvimento do projeto para serem apresentados na Feira de Ciências. Pois além, dos alunos escolherem os conteúdos que serão expostos durante o evento, as orientações dos professores é de suma importância neste processo de ensino, já que o docente traz uma certa experiência de como se dá o desenvolvimento da feira de ciências. Neste sentido, segundo o autor Passmore (1980, p. 20) complementa a ideia proposta, 
algumas vezes "visar promover a aprendizagem" e, outras "conseguir efetivamente promove-la”, isto é, umas vezes refere-se a uma tentativa, outras vezes, ao seu sucesso (PASSMORE, 1980, p. 20).

Daí a importância das orientações dos professores na elaboração dos projetos a serem apresentados na Feira de Ciências. O professor busca com essas orientações, facilitar a aprendizagem dos alunos, para que o mesmo possa alcança o conhecimento Científico e Tecnológico. Durante esse processo de ensinar o professor aproveita o momento em que eles se encontram motivados no desenvolvimento do projeto.

A Figura 4 apresenta as respostas dos professores em relação ao tempo de duração da pesquisa?

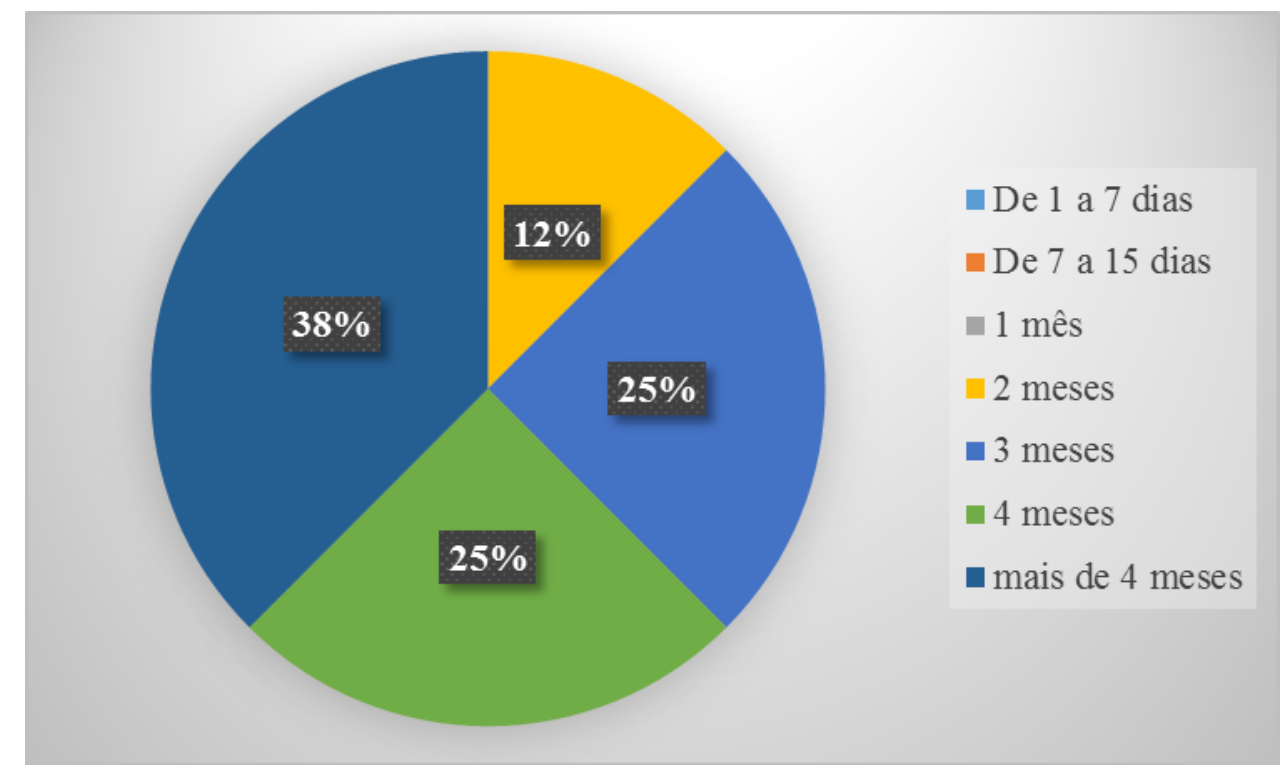

Figura 4 - Tempo dispendido para cada professor para a organização da Feira de Ciências

Nota-se que o tempo para o planejamento, elaboração e execução da pesquisa foi extenso, isso demonstra que os professores e alunos se empenharam bastante no desenvolvimento de suas pesquisas para encontrar soluções para os problemas da comunidade. Essas soluções encontradas são apresentadas para a comunidade nas Feiras de Ciências, promovendo uma Alfabetização Científica da comunidade.

Dessa forma, as Feiras de Ciências devem se tornar espaços representativos dos reais interesses dos alunos e da busca de soluções para os seus problemas e para os problemas de suas comunidades. Promover feiras ou apresentações dos projetos deve ser visto como um meio de propiciar a comunicação entre a comunidade e a escola, 
contribuindo para o que se tem denominado de "Alfabetização Científico-Tecnológica" dos visitantes (NEVES; GONÇALVES, 1989).

A sétima pergunta, buscou saber de que forma esse projeto contribuiu para o processo de aprendizagem do estudante e segundo as respostas dos professores:

Professor 1 - No momento da busca sobre o assunto e principalmente quando ocorre a apresentação do projeto, eles sabem tanto, que até se espanto;

Professor 2 - Os alunos podem conectar teoria e prática e perceber que os conceitos estão presentes no dia a dia;

Professor 3 - Incentivo os alunos a pesquisarem para terem perspectivas de soluções de problemas, aprimorando o seu conhecimento;

Professor 4 - Contribui possibilitando o contato com outra realidade adversa a dele;

Professor 5 - Pode contribuir para inteligências múltiplas (professores). Etc...

Observa-se que os professores, afirmam durante a pesquisa que os projetos desenvolvidos para serem apresentados na Feira de Ciências contribuem para o processo de aprendizagem. Para Wanderley (1999), as Feiras de Ciências, devem ser iniciadas com o desejo do aluno de trabalhar uma ideia e culminar na apresentação pública do trabalho. Essa trajetória trilhada pelos participantes, alunos, professores e visitantes pode contribuir para diferentes níveis de cognição uma vez que tais caminhos se apresentam como oportunidades continuadas e desafiantes de interação entre os participantes e o objeto do conhecimento, favorecendo assim a evolução do pensamento conceitual.

$\mathrm{Na}$ oitava pergunta, questionou-se, quais os pontos positivos e negativos observados durante a realização do projeto e apresentação na Feira de Ciências e de acordo com os professores:

Professor 1 - Tudo ótimo;

Professor 2 - Falta de apoio das escolas e divulgação da Feira de Ciências;

Professor 3 - Não houve pontos positivos e nem negativos;

Professor 4 - Alunos tem dificuldades com a construção do projeto;

Professor 5 - Interesse do grupo pelo tema;

Professor 6 - A participação de alunos com necessidades especiais e a falta de recursos didáticos e tecnológicos (professores). Etc...

Percebe-se que os professores, indicam tanto pontos positivos quanto negativos observados durante a Feria de Ciências. Em relação aos pontos negativos, mesmo diante de todas essas dificuldades podemos considerar que o projeto desenvolvido acaba por 
ser significativo, tanto para os alunos, quanto para os professores, pois, as Feira de Ciência tem o intuito de divulgar a produção científica e tecnológica de modo a propiciar um ambiente de ensino-aprendizagem fértil, possibilitando um sucesso maior nessa empreitada. Borba (1996) traz alguns pontos positivos deste evento:

"A Feira de Ciências desenvolve no aluno a ação democrática de participação coletiva. Permite a troca de experiências, libera o aluno para um pensar criativo em que a sua capacidade de comunicação é exercitada. Consequentemente, após atuar em uma Feira de Ciências, nosso aluno retornará à sala de aula com maior capacidade de decisão em relação aos problemas do nosso cotidiano" (p. 43).

$\mathrm{Na}$ nona pergunta, indagou-se, aos professores o qual o seu entendimento sobre Divulgação Científica e todos os professores mencionaram que Divulgação científica é:

Professor 1 - Apresentação das pesquisas para a sociedade em geral;

Professor 2 - Levar o conhecimento científico a todos de forma clara e lúdica;

Professor 3 - Significa divulgar projetos que possam modificar aspectos sociais e humanos

Professor 4 - Socialização de projetos e pesquisas;

Professor 5 - Levar ciências de forma clara as pessoas (professores). Etc...

Todos os professores trazem respostas direcionado a Divulgação Científica, mas para o conceito de 'divulgação científica', Bueno (1984. p. 18) diz:

Compreender o uso de recursos técnicos e processos para a veiculação de informações Científicas e Tecnológicas ao público em geral. Essa atividade pressupõe um processo de recodificação de uma linguagem especializada visando a tornar seu conteúdo, de acesso fácil a uma vasta audiência (BUENO, 1984. p. 18).

Bueno (1984. p. 19) ressalta ainda que:

A "Divulgação Científica, muitas vezes denominada popularização ou vulgarização da Ciência, tem sido reduzida à veiculação de informações de ciência e tecnologia pela imprensa" coincidindo com o conceito de jornalismo científico. Nesse contexto as Feiras de Ciências é tipo de recurso técnico de veiculação da informação científica (BUENO, 1984. p. 19).

Garroti (2014, p. 35) reforça ainda que:

Há diversas formas de divulgar ciência para o público leigo: artes (cinema, teatro, quadrinhos, música, poesia, enfim, diversos canais); jornalismo 
científico (desde o das grandes mídias, TVs, documentários, até o das regionais/locais, passando pelos meios eletrônicos e digitais, como blogs de ciência); palestras, cursos variados, redes sociais, dentre muitos outros formatos.

$\mathrm{Na}$ decima pergunta foi questionado, qual o objetivo da Feira de Ciências e segundo as respostas dos professores:

Professor $1_{-}$- Troca de conhecimento;

Professor 2 - Divulgação científica;

Professor 3 - Apresentação de projetos que sirvam para melhorar a vida em sociedade;

Professor 4 - Socialização de ideias (Professores). Etc...

As respostas dos professores estão mais direcionadas para a Divulgação Científica e pouco relacionadas com os objetivos das feiras de ciências. Assim, segundo Pereira et al. (2000), as Feiras de Ciências têm como objetivo propiciar um conjunto de situações de experiências que possibilitem:

\footnotetext{
....incentivar a atividade científica; favorecimento da realização de ações interdisciplinares; estimular o planejamento e execução de projetos; estimular o aluno na busca e elaboração de conclusões a partir de resultados obtidos por experimentação; desenvolver a capacidade do aluno na elaboração de critérios para compreensão de fenômenos ou fatos, pertinentes a qualquer tipo, quer cotidiano, empírico ou científico; proporcionar aos alunos expositores uma experiência significativa no campo sócio - científico de difusão de conhecimentos; integração da escola com a comunidade (PEREIRA et al. 2000, p. 20).
}

Por fim, a última questão, buscou saber qual o entendimento dos professores sobre a contribuição das Feira de Ciências para Divulgação Científica em Roraima? justificando essa contribuição da seguinte forma:

Professor 1 - É nosso trabalho mesmo;

Professor 2 - É o único evento de Ciências em Roraima;

Professor 3 - Serve para projetar e atualizar Roraima no âmbito de ensino nacional;

Professor 4 - Difundir os trabalhos dos alunos, Divulgação Científica" (Professores). Etc...

Evidencia-se, pelas respostas dos professores que as feiras de ciências contribuem para Divulgação Científica em Roraima. Elas podem oportunizar a socialização do conhecimento científico e tecnológico para professores e alunos e a comunidade. Nesse sentido, a realização da feira e outros eventos de ciência apontam mudanças positivas 
aos alunos e professores que se evidenciam durante e a partir dos processos de investigação provocados por estes eventos. As atividades da feira de ciências podem contribuir para desenvolver ações democráticas de participação coletiva, permite trocas de experiências, libera o aluno para um pensar criativo, em que sua capacidade de comunicação é exercitada (BORBA, 1996).

\section{CONSIDERAÇÕES FINAIS}

Constata-se que os professores apresentam concepções diferentes sobre feira de ciências, mas por terem pontos de vista heterogêneos a maioria já tem uma certa experiência como planejar, desenvolver e executar os projetos a serem apresentados na feira. Na realização dos projetos os alunos são responsáveis pela escolha do tema a ser trabalhado na pesquisa e durante esse processo o professor fica encarregado das orientações.

Os alunos participam de forma plena no desenvolvimento do projeto e são bastante motivados e criativos, o tempo de realização dos projetos varia de dois (2) meses a mais de quatro (4) meses de estudo e pesquisa o que vem a contribuir para uma aprendizagem científica e tecnológica dos alunos. Como todo projeto tem suas dificuldades, o mais importante é supera-las. Os professores tem conhecimentos empíricos sobre divulgação científica, mas não direcionados especificamente para o próprio conceito do que é realmente divulgação científica. As feiras de ciências podem contribuir para divulgação científica em Roraima, divulgado a produção científica e cultural dos alunos e do próprio estado.

\section{REFERÊNCIAS}

ALBAGLI, S. Divulgação científica: informação científica para a cidadania? Ciência da informação, v. 25, n. 3, p. 396-404, 1996.

BUENO, W. C. Jornalismo científico no Brasil: os compromissos de uma prática dependente. 1984, 364 f. Tese (Doutorado) - USP, ECA, São Paulo, 1984.

BUENO, W. C. B. Comunicação científica e divulgação científica: aproximações e rupturas conceituais. Inf. Inf., Londrina, v. 15, n. esp, p. 1 - 12, 2010.

BORBA, Edson. A importância do trabalho com Feiras e Clubes de Ciência. Repensando o Ensino de Ciências. Caderno de Ação Cultural Educativa. Vol. 03, 
coleção Desenvolvimento Curricular. Secretaria de Estado da Educação de Minas Gerais. Belo Horizonte, 1996.

FENACEB, 2006. Programa Nacional de Apoio às Feiras de Ciências da Educação Básica.

Disponível em: <http://portal.mec.gov.br/seb/arquivos/pdf/EnsMed/fenaceb.pdf>. Acesso em: 24 dez. 2018.

FOUREZ, G. A construção das ciências: introdução à filosofia e à ética das ciências. São Paulo: Editora da Universidade Estadual Paulista, 1995.

GARROTI, Carina Pascotto. Semana Nacional de Ciências e Tecnologia no Brasil: Avanços e desafios. Campinas, SP: (s.n.), 2014.

GIL, Antonio Carlos. Como elaborar projetos de pesquisas. 4. Ed. São Paulo: Atlas, 2008.

MANCUSO, R. Programa estadual de Feiras de Ciências do Rio Grande do Sul. Porto Alegre: SEC/CECIRS, 1995.

NEVES, S. R. G.; GONÇALVES, T. V. O. Feiras de Ciências. Caderno Catarinense de Ensino de Física, v.6, n.3, p. 241, 1989.

ORMASTRONI, Maria Julieta Sebastiani. Manual de Feira de Ciências. Brasília: CNPq, AED, 1990.

PASSMORE, John. 1980. The Philosophy of Teaching. London: Duckworth. Trad.: Pombo, Olga (1994/1995)

PEREIRA, A. B. \& Oaigen, E.R. \& Hennig. G. Feiras de Ciências. Canoas: Ulbra, 2000 .

ROSA, P.R.S. Algumas Questões Relativas A Feiras De Ciências: Para Que Servem E Como Devem Ser Organizadas. Cad. Cat. Ens. Fís., v. 12, n. 3: p. 223-228, 1995.

SANTOS, W. L. P; Schnetzler, R. P. Educação em química: compromisso com a cidadania. Ijuí: UNIJUÍ, 1997.

SOUSA, M. S. M. 2015. As feiras de ciências em Roraima no período de 1986 a 2008: contribuição para a iniciação à educação científica. Dissertação de Mestrado na Universidade Estadual de Roraima - UERR. Boa Vista.

WANDERLEY, E. C. 2001. Feiras de Ciências Enquanto Espaço Pedagógico para Aprendizagens Múltiplas. In: Silvério Crestana. (Org.). Educação para a Ciência curso de Treinamento em Centros e Museus de Ciências. 1 ed. São Paulo: Editora Livraria da Física, v. 1, p. 269-274. 


\section{APÊNDICE 1}

1. Qual o seu entendimento sobre as Feiras de Ciências?

( ) Evento pedagógico

( ) Evento científico

( ) Projeto de ensino e pesquisa

( ) Projeto de pesquisa

( ) Projeto de ensino

( ) Espaço de divulgação científica

( ) Outros:

2. Já participou de Feiras de Ciências como estudante?

( ) Sim ( ) Não

3. Como é escolhido o tema para desenvolver o projeto de pesquisa com os estudantes?

( ) Escolhido pelos alunos

( ) Escolhido pelo professor regente

( ) Escolhido pelo professor da disciplina

( ) Escolhido pelo coordenado pedagógico

( ) Outros:

4. Como se dá o envolvimento dos estudantes durante a realização do projeto?

5. Como ocorre o processo de orientação durante a realização do projeto?

6. Quanto tempo durou a pesquisa?

( ) de 1 a 7 dias

( ) de 7 a 15 dias

( ) 1 mês

( ) 2 meses

( ) 3 meses

( ) 4 meses

( ) mais de 4 meses

7. No seu entendimento de que forma esse projeto contribuiu para om processo de aprendizagem do estudante? 
8. Quais os pontos positivos e negativos observados durante a realização do projeto e apresentação na Feira?

9. No seu entendimento o que é divulgação científica?

10. Qual o objetivo da Feira de Ciência?

11. No seu entendimento a Feira de Ciências contribui para a divulgação científica em Roraima? 